\title{
Reverse Innovation: A significant perspective for the Baltic companies
}

\author{
Bahman Peyravi
}

\begin{abstract}
:
Innovation performance of the Baltic countries (BC) has shown stable performance in recent years and it is still behind European Union (EU) average. The most important evidence of this approach is the results of European Innovation Scoreboard (EIS). This paper presents "Reverse Innovation" as ignition power for BC's medium and large firms and in this context, higher innovation performance for BC among EU countries. Furthermore, this paper examines factual results of reverse innovation in different cases in order to present significant background for understanding of medium and large Baltic enterprises. Through analysis of the statistics from the EIS and various practical cases of reverse innovation, the paper tries to emphasize on the importance of reverse innovation for medium and large firms in BC.
\end{abstract}

Keywords: Innovation; Reverse Innovation; Baltic countries; European Union; Innovation performance. 